\title{
Una pastoral ordinaria más misionera desde la V Conferencia de Aparecida. O ¿cómo la renovación misionera interpela a las estructuras pastorales?
}

DOI: https://doi.org/10.52039/seminarios.v54i188.534

VÍCTOR MANUEL FERNÁNDEZ

La lectura del presente artículo nos ayuda a clarificar algunos aspectos a los lectores de esta revista: la identidad de la pastoral en América Latina, que tiene su palabra enriquecedora en la pastoral europea. El autor, teólogo y pastor nos regala una visión de la $\mathbf{V}$ Conferencia Aparecida dinámica, reflexiva, creativa y prospectiva. Baste citar cómo el autor trata el tema de la pastoral popular releyendo ese paradigma desde la misión ad gentes. Por último, las recomendaciones del autor sobre la evangelización de nuestro tiempo que desarrolla en el punto 10., nos invitan de nuevo al debate y a la reflexión.

Introducción.- 1. ¿Un perfil cristiano más misionero para este nuevo siglo? (49); 2. De qué manera la convocatoria misionera afecta a todos (51); 3. Cómo entender adecuadamente la misión en América Latina y el Caribe (53); 4. La misión en su modalidad de pastoral popular (55); 5 . Misión ad gentes y nueva inculturación dentro de América Latina (59); 6. El nuevo llamado misionero (60); 7. La renovación extática, kerigmática y vocacional de la pastoral ordinaria (61); 8. La dimensión discipular de la propuesta (65); 9. Agentes pastorales cargados de propuestas de vida (67); 10. Misión, dignidad humana y espiritualidad contra la obsesión por el tiempo (70). 
En este momento histórico es inevitable que surja dentro de nosotros la pregunta: ¿Qué pasará con la Iglesia dentro de unos años? Pero al mismo tiempo brota a veces otra pregunta: ¿Qué pasa conmigo? ¿Qué está ocurriendo con mi vocación? ¿Qué sucede con mi fervor apostólico?

Sabemos que en esta época de caída de las utopías, tiempo de desencanto y escepticismo cómodo, también se han derrumbado ciertos estereotipos de la identidad cristiana que antes brindaban seguridad, autoestima y fervor eclesial. Pero no parece que todavía haya surgido una figura alternativa, un ideal cristiano que tenga la virtud de provocar efectos semejantes, es decir, que permita sostener hoy una identidad comunitaria gozosa y una entrega generosa de la propia vida. Aun los seminarios y centros de formación sacerdotal están en búsqueda con respecto a la identidad en la cual deben formar, porque entienden que si no hay un perfil presbiteral suficientemente firme y atractivo, los sacerdotes de hoy y de mañana difícilmente darán la vida en el ministerio. En medio de sus tareas vivirán la angustia de no poseer una identidad clara. Pero este fenómeno se ha generalizado, y aumenta la bibliografía referida no sólo a la identidad sacerdotal, sino a la identidad específica del catequista, del religioso, del laico consagrado, etc.

En realidad, es muy valioso que así sea, porque tanto el propio ser como la misión que uno tiene en el mundo suponen un mismo llamado divino que les da origen. Es el único llamado del Dios amante que al mismo tiempo que me constituye en esta persona singular me otorga una misión singular. No es una misión que tengo sino que soy, porque Dios, al 'llamarnos' a cada uno, en 'un mismo acto' nos entrega nuestro nombre y nuestra misión en la vida ${ }^{1}$. En el cumplimiento de esa misión nos vamos construyendo como personas y alcanzando una identidad plena, la satisfacción de saber para qué estamos y por lo tanto quiénes somos. Por eso, cuanto mayor sea la identificación de cada uno con la misión encomendada por Dios, más rica será su identidad y más definida y plena aparecerá su personalidad 2 .

Por otra parte, cada ministerio o servicio eclesial tiene algunas notas esenciales e invariables, pero también tiene otras más histórico culturales. Son características que, por su inserción mundana y evangelizadora, pueden marcar a los agentes pastorales en una época determinada. Tienen que ver con lo que la Iglesia discierna para cada momento histórico, pero también con lo que cada uno configure de acuerdo a su identidad personal y a sus carismas peculiares. Hay una serie de características y de tareas que pueden variar de un lugar a otro y de una diócesis a otra. Por eso, en cada

1 E. Terrasa, El viaje hacia la propia identidad, Pamplona, 2005, 72.

2 Ibíd, 73. 
diócesis, el obispo, los sacerdotes, los/as religiosos/as, los diáconos y los/as laicos/as pueden delinear un determinado perfil que consideren adecuado para ese lugar. Todos los agentes pastorales están llamados a inculturarse en la tierra donde viven con el mismo 'afecto' con que Cristo se unió por su encarnación 'a las determinadas condiciones sociales y culturales' de los hombres con quienes convivió (AG 10), y a reflejar su fe en el ambiente de la sociedad y de la cultura patria, según las tradiciones de la nación (AG 21). Esto implica encarnarse en las aspiraciones, las riquezas, los límites, las maneras de orar, de amar, de considerar la vida que distinguen a tal o cual conjunto humano (EN 63). El perfil básico y permanente de todos los agentes pastorales debe ser reelaborado comunitariamente en cada lugar y en cada etapa, reconociendo ante todo lo que Dios mismo quiere comunicar al mundo en ese contexto. Sólo así es posible apasionarse con un ideal de entrega cristiana y proponerlo vocacionalmente a otros.

Esto mismo puede ayudar a tomar una decisión muy honda que nos lleve a identificarnos a fondo con un modo de ser cristianos en una determinada entrega vocacional. Si esta decisión no es radical y totalizadora, con el paso del tiempo pretenderemos buscar momentos de liberación o de disimulo de lo que somos, tratando de desligarnos completamente de ello, y así terminaremos cansados por la tensión interna que provoca esa esquizofrenia, nos quemaremos por dentro a causa de esa falta de unidad personal. Para que esto no suceda es necesario haber percibido la belleza y el atractivo de la propia vocación, no porque sea superior a las demás, sino porque es la que Dios me regala como parte esencial del sentido de mi vida, y que me configura en mi identidad de ser para los demás siempre, sin reposo.

La V Conferencia General del Episcopado Latinoamericano y Caribeño (Aparecida: DA) ha cargado las tintas en una invitación a repensar la identidad de todo agente pastoral, y por consiguiente toda la pastoral ordinaria, a la luz de la misión ad gentes. Veamos lo que esto significa.

\section{1. ¿Un perfil cristiano más misionero para este nuevo siglo?}

Si algo caracterizó a la $V$ Conferencia es su contundente invitación a la misión y su llamado a transformar todas las estructuras eclesiales (abandonando algunas de ellas si es necesario) para que sean claramente misioneras. Se trata de un nuevo dinamismo misionero que genere un estado permanente de misión, de manera que así la Iglesia vuelva a ser fiel a su identidad más profunda. Esa misión se realiza con la profunda convicción de que al llevar el Evangelio estamos ofreciendo una vida más digna y más 
plena. El dinamismo misionero, que debe transfigurar todas las estructuras, todas las opciones, todas las tareas, también invita a repensar el perfil de cada cristiano de manera que su identidad y su formación se orienten efectivamente a la misión permanente. Esta invitación parece contradecir lo propio de la vocación de un padre de familia, que no puede ser un nómada, o parece despreciar el profundo arraigo en un lugar que caracteriza al sacerdote diocesano. Los catequistas, por su parte, podrían objetar que ellos están llamados a hacer crecer la fe, y no al anuncio misionero. Vemos así que no faltan las acostumbradas y muy razonables excusas.

Además, cabe reconocer que en el siglo XX disminuyó notablemente la actividad misionera de muchas congregaciones religiosas, que se localizaron, dedicándose a atender centros educativos o a colaborar en parroquias. El desencanto posmoderno, la caída de las utopías y el desarrollo de un subjetivismo individualista y cómodo agravan aún más la caída del ardor misionero. Esto ayuda a percibir cuán oportuna fue la encíclica Redemptoris Missio. ${ }^{3}$ La reflexión de Juan Pablo II nos invitó a reconocer que es necesario mantener viva la solicitud por el anuncio a los que están alejados de Cristo, porque esa es la tarea primordial de la Iglesia (RMi 34) y la actividad misionera representa, también hoy día, 'el mayor desafío' para la Iglesia (RMi 40). Nos guste o no, para el creyente en singular, lo mismo que para toda la Iglesia, 'la causa misionera debe ser la primera' (RMi 86).

Ante expresiones tan contundentes no podemos permanecer indiferentes, y un sentido eclesial responsable nos exige, al menos, que nos preguntemos de qué manera concreta estamos dispuestos a responder a tal interpelación.

Para salir al paso a posibles excusas, Juan Pablo II indicó que el contexto cultural actual, lleno de novedosos e impresionantes desafíos, no debería ser visto como una amenaza sino como una oportunidad para renovar un dinamismo misionero apagado y débil: En la historia de la humanidad son numerosos los cambios periódicos que favorecen el dinamismo misionero. La Iglesia, guiada por el Espíritu, ha respondido siempre a ellos con generosidad y previsión (RMi 30). También afirmó que el balance de la actividad misionera en los tiempos modernos es ciertamente positivo (RMi 40). Las Iglesias locales fundadas en América, Asia y África deben su existencia a una labor misionera ardua y perseverante. La pregunta es qué estamos preparando nosotros en esta época posmoderna, qué legado dejaremos a las siguientes generaciones. Podemos ceder al fatalismo o podemos reco-

3 Cf. P. Thion, "Retour aux missions? Une lectura de l'encyclique Redemptoris Missio", en Nouvelle Révue Théologique 114 (1992), 69-86. 
nocer en los nuevos desafíos verdaderas posibilidades que estimulen un nuevo ardor evangelizador:

Nunca como hoy la Iglesia ha tenido la oportunidad de hacer llegar el Evangelio, con el testimonio y la palabra, a todos los hombres y a todos los pueblos. Veo amanecer una nueva época misionera, que llegará a ser un día radiante y rica en frutos si todos los cristianos, y en particular los misioneros y las jóvenes iglesias, responden con generosidad y santidad a las solicitaciones y desafíos de nuestro tiempo (RMi 92).

Por eso, ha llegado el momento de dedicar 'todas' las fuerzas eclesiales a la nueva evangelización y a la misión 'ad gentes' (RMi 3). Hoy hace falta pasar a la acción, porque se nos plantea la urgencia de la actividad misionera (RMi 1).

Podemos optar, como hicieron otros cristianos en épocas tan difíciles como la nuestra, por entregarnos con arrojo confiado en un anuncio lleno de fascinación, o podemos entretenernos en el diagnóstico inerme e ineficaz, en el lamento cómodo y pusilánime, en el apático y gris pragmatismo lleno de excusas egoístas.

Pero hubo que esperar hasta Aparecida para que el desafío misionero lanzado por Juan Pablo II y renovado por Benedicto XVI fuera debidamente acogido en América Latina.

\section{De qué manera la convocatoria misionera afecta a todos}

En general, los que no somos misioneros, tenemos una serie de prejuicios en lo que respecta a la misión. Por eso, se vuelve necesario clarificar el sentido completo y exacto de la convocatoria misionera, de manera que pueda ser asumida por todos y cada uno desde su vocación específica. Sobre todo si tomamos conciencia e intentamos asumir que no se trata de un área secundaria de la pastoral de la Iglesia, o de un aspecto más al lado de tantos otros.

Este momento histórico es una invitación a devolver a nuestras comunidades su calidad misionera constitutiva y esencial:

Esta firme decisión misionera debe impregnar todas las estructuras eclesiales y todos los planes pastorales de diócesis, parroquias, comunidades religiosas, movimientos y de cualquier institución de la Iglesia. Ninguna comunidad debe excusarse de entrar decididamente, con todas sus fuerzas, en los procesos constantes de renovación misionera, y de abandonar las estructuras caducas que ya no favorezcan la transmisión de la fe. La conversión personal despierta la capacidad de someterlo todo al servicio de la instauración del Reino de vida (DA 365366). 
Pero cuando el Espíritu quiere producir una renovación en la Iglesia, el miedo y la comodidad siempre llevan a oponer resistencias, incluso teológicas. Por ejemplo, cuando englobamos dentro de la expresión misión toda la actividad pastoral de la Iglesia, hasta el punto que entendemos que el simple cumplimiento de nuestras tareas ordinarias ya es nuestra respuesta al llamado misionero y nuestra participación en la tarea misionera de la Iglesia. La Redemptoris Missio también salió al paso de este planteo simplista. Explicó que la misión ad gentes, a la cual estamos llamados todos, sin excepción, es diferente de la atención pastoral ordinaria. Se dirige a pueblos, grupos humanos, contextos socioculturales donde Cristo y su Evangelio no son conocidos o donde faltan comunidades cristianas suficientemente maduras (RMi 33).

En América Latina, la misión asume características peculiares cuando se dirige a personas que ya no se consideran católicas y han ido debilitando su identidad cristiana hasta prescindir de Jesucristo en sus vidas, aunque vivan en lugares caracterizados por una cultura de raíz católica. Se trata de la llamada reevangelización o nueva evangelización. Redemptoris Missio la describe como un anuncio kerygmático dirigido a personas que, viviendo en lugares de tradición católica, no se reconocen ya como miembros de la Iglesia, llevando una existencia alejada de Cristo y de su Evangelio (RMi 33). Este fenómeno se explica por las características del mundo actual donde muchas veces los padres bautizados ya no dedican tiempo a sus hijos, no les transmiten la fe católica, y llevados por la vorágine de la vida posmoderna, algunos ni siquiera llevan a sus hijos a bautizar. En esas familias están los típicos destinatarios de una nueva evangelización, que se ve facilitada porque en general no se sitúa en el contexto de un rechazo explícito o de una ignorancia total de la propuesta cristiana, pero que puede estar condicionada por una situación de indiferencia, de desinterés, o incluso de prejuicios negativos generados por los medios de comunicación. Por otra parte, la situación de los hijos de estas familias, que ya ni siquiera fueron bautizados, comienza a integrar el campo de la misión ad gentes en sentido estricto.

Estas distinciones, aunque necesarias, son insuficientes para entender el sentido de la misión en América Latina y el Caribe. En efecto, si la reevangelización o nueva evangelización se dirige a personas que ya no se reconocen como miembros de la Iglesia, llevando una existencia alejada de Cristo y de su Evangelio, esto no puede decirse estrictamente de la mayor parte de los latinoamericanos. Esta modalidad de la misión es fácilmente aplicable a varias regiones de Europa, pero no tanto a la mayoría de los pobladores de América latina, quienes siguen reconociéndose como miembros de la Iglesia Católica, y, a su modo, llevan una existencia íntimamente conectada con Cristo y con su Evangelio. Sin embargo, tampoco se les 
aplica fácilmente la categoría de atención pastoral ordinaria, puesto que la mayoría de ellos no asiste a la Misa dominical y no integra grupos o instituciones de parroquias o movimientos católicos, de manera que las estructuras ordinarias de la Iglesia no llegan a ellos.

\section{Cómo entender adecuadamente la misión en América Latina y el Caribe}

En Aparecida encontramos una valoración de la piedad popular más positiva que en cualquier otro documento del magisterio universal e incluso latinoamericano. No contiene las advertencias y reparos que aparecían incluso en Puebla. Sólo indica los límites de la piedad popular invitando a promover su crecimiento en una mayor inserción eclesial de los fieles que se realice particularmente en la participación frecuente en la Eucaristía dominical, y también en un contacto más directo con la Biblia (DA 262). Esta invitación no tiene un sentido dialéctico, sino que propone un crecimiento a partir de la riqueza peculiar que identifica a la misma piedad popular.

Por eso hay que evitar el error frecuente de equiparar la predicación en estos sectores populares con la predicación en lugares no cristianos. Hoy los teólogos enseñan de modo casi unánime que no sólo es posible la salvación de los paganos, sino que la gracia del Espíritu puede actuar por otros caminos en los corazones de miles de millones de personas que no creen en Jesucristo. ${ }^{4}$ Para estas personas no hay otro plan de salvación, sino que se asocian misteriosamente a la Pascua de Jesucristo (cf. GS 22). Viven de Cristo de modo real, aunque implícito. ¿Eso mismo se dice con respecto a los fieles penetrados por la piedad popular católica? ¿Decimos que la misión tiene sentido para que expliciten algo que ellos están viviendo implícitamente? Por supuesto que no.

Para comprender mejor lo que estamos diciendo consideremos brevemente un valioso documento de la Comisión Teológica Internacional, El Cristianismo y las Religiones. ${ }^{5}$ El documento indica que la gracia del Espíritu Santo actúa también en los no cristianos, que se unen al Misterio Pascual por caminos que Dios conoce (GS 22), de modo que también ellos pueden

\footnotetext{
4 Después de RMi 55, lo ha reafirmado la Congregación para la Doctrina de la Fe en su Nota doctrinal acerca de algunos aspectos de la evangelización, 03/12/2007, 7: Los no cristianos pueden salvarse mediante la gracia que Dios da a través de caminos que Él sabe.

5 Comisión Teológica Internacional, El Cristianismo y las Religiones, publicado en Gregorianum 79/3 (1998), 427-472. Lo citamos CR.
} 
estar justificados por la gracia de Dios (CR II.4; 72). Esto no implica una actividad universal del Espíritu desligada de Jesucristo (CR II.3; 53), ya que la acción del Espíritu siempre se orienta al encuentro pleno con el Cristo del Evangelio y a una comunión visible en la Iglesia (CR I.6; 24). Por eso mismo no podemos renunciar al anuncio explícito de Cristo, mostrando la inaudita cercanía de Dios que se ha realizado en la Encarnación. Precisamente cuando afirmaba que los seguidores de otras Religiones pueden recibir la gracia, Juan Pablo II invitaba a dialogar con ellos con la convicción de que la Iglesia es el camino ordinario de salvación y que sólo ella posee la plenitud de los medios de salvación (RMi 55c).

La plenitud que alcanza un no cristiano en la adhesión a Cristo y a su Iglesia no es sólo una explicitación intelectual de lo que ya tenía, porque no significa solamente una tematización de la trascendencia, sino la mayor 'realización' de la misma (CR I, 6; 24). El Espíritu no sólo obra el paso del estado de pecado a la vida en gracia, sino que derrama en la Iglesia Católica plenitud de posibilidades de conocimiento, de contemplación, de celebración, de comunión, de discernimiento, de testimonios explícitos y de riqueza de dones, en orden a que la vida en gracia no sea sólo un germen que basta para salvarse, sino que alcance su pleno y totalizante desarrollo en la existencia del ser humano. El contexto de la Iglesia Católica no sólo permite un conocimiento explícito de Cristo, ausente en los no cristianos, sino una plenitud de medios en orden al crecimiento de todos los aspectos de la vida en gracia, y no sólo de su aspecto cognoscitivo. Es decir, la gracia puede alcanzar en la Iglesia su máxima y más perfecta expresión, puede explayarse con su mayor riqueza.

Pero demos un paso más. La experiencia sacramental es una dimensión de la gracia que responde a la realidad sensible del ser humano y prolonga el misterio de la Encarnación. La gracia, que procede del Verbo encarnado, tiene siempre un dinamismo encarnatorio que la orienta a expresar la vida en Cristo de modo externo y sensible. Pero precisamente eso, que es tan pobre en la experiencia de gracia que puede vivir un no cristiano, es lo que está presente de un modo abrumador en la piedad popular. Allí no podemos decir, como afirmamos de las Religiones, que puede estar presente la acción invisible de la gracia pero que falta su manifestación y realización externa, sensible, explícita. Al contrario, si algo se destaca en la piedad popular es la manifestación sensible y sacramental de la fe expresamente católica. Es una espiritualidad cristiana que, siendo un encuentro personal con el Señor, integra mucho lo corpóreo, lo sensible, lo simbólico, y las necesidades más concretas de las personas. Es una espiritualidad encarnada en la cultura de los sencillos, que, no por eso, es menos espiritual, sino que lo es de otra manera (DA 263). Caminar de rodillas hacia el crucificado y besar una cruz con lágrimas en los ojos no es implícitamente cris- 
tiano, sino explícitamente católico. En la mirada amorosa y confiada a una imagen de la Virgen no hay un cristianismo implícito, sino explícitamente católico, porque en esa imagen el corazón creyente lee el Evangelio y ante ella expresa su confianza cristiana. Es más, cuando la mayoría de los fieles de nuestros países llevan a sus hijos a bautizar, están manifestando su clara inserción en la Iglesia Católica y el reconocimiento creyente de los medios sacramentales de salvación presentes en ella.

La piedad popular es una manera legítima de vivir la fe, un modo de sentirse parte de la Iglesia y una forma de ser misioneros, donde se recogen las más hondas vibraciones de la América profunda (DA 264). Su fuerza sacramental es tan intensa que ha llegado a trasfigurar las culturas de nuestros pueblos. Es un cristianismo profundamente inculturado, que contiene la dimensión más valiosa de la cultura latinoamericana (DA 258). Entonces, la evangelización de la piedad popular sólo procura un desarrollo de algo que ya es propia y explícitamente cristiano según su modo cultural propio. Aparecida se expresa con mucha precisión al respecto:

Cuando afirmamos que hay que evangelizarla o purificarla, no queremos decir que esté privada de riqueza evangélica. Simplemente, deseamos que todos los miembros del pueblo fiel, reconociendo el testimonio de María y también de los santos, traten de imitarles cada día más. Así procurarán un contacto más directo con la Biblia y una mayor participación en los sacramentos, llegarán a disfrutar de la celebración dominical de la Eucaristía, y vivirán mejor todavía el servicio del amor solidario. Por este camino, se podrá aprovechar todavía más el rico potencial de santidad y de justicia social que encierra la mística popular (DA 262).

Desde esta perspectiva, que no niega la presencia de la Vida sino que reconoce el llamado del Espíritu a la plenitud, el Episcopado argentino, en sus líneas pastorales de 2003, presentó una de las acciones destacadas como acompañar a todos los bautizados hacia el pleno encuentro con Jesucristo (NMA 90-92). Es la misma perspectiva presente en Aparecida, que presenta la misión como ofrecimiento de una vida plena. En este sentido, ya decía hace varías décadas De Lubac que las misiones no son tanto una cuestión de vida o muerte sino de 'plenitud' de vida", 6 aunque él se refería a la presencia de la vida del Espíritu en los no cristianos, y nosotros nos referimos a esa vida en Cristo, llena de hermosura sacramental, que reclama aun más su plenitud eucarística y eclesial.

\section{La misión en su modalidad de pastoral popular}

Por todo lo dicho, la misión dirigida a las multitudes que viven su fe católica

6 H. De Lubac, Le fondement théologique des missions, Paris, du Seuil, 1946, 37. 
según el modo propio de la piedad popular, no se orienta entonces a explicitar mejor una acción invisible de la gracia, sino a llevar a plenitud una manera legítima de vivir la fe (DA 264). Aparecida llega a hablar de una verdadera mística popular (DA 262), una expresión de sabiduría sobrenatural y verdadera espiritualidad cristiana (DA 263). Sin embargo, invita a llevar esa piedad a una experiencia más plena. Reconozcamos que esa plenitud debería resultarnos imperiosa si tenemos un corazón realmente misionero, ya que se trata nada menos que de propiciar la lectura orante de la Palabra y la participación en la celebración comunitaria de la Eucaristía, desarrollando así una más plena inserción eclesial. Nadie puede negar que, si la acción secreta de la gracia en un pagano reclama la plenitud eucarística, con mayor razón hay que decirlo de fieles católicos que viven su fe con profunda devoción. Sin pretender culparlos a ellos de semejante contradicción, la actividad evangelizadora de la Iglesia debería ocuparse de eliminar los condicionamientos de todo tipo que impiden que la vida de la gracia, presente y manifiesta en millones de fieles católicos, pueda lograr esa plenitud eucarística a la que tiende por su propia naturaleza, como las copas de los árboles buscan incesantemente la luz del sol y como las raíces reclaman sedientas la humedad de la tierra profunda. Si es propio de la Iglesia Católica poseer y ofrecer una plenitud de medios de salvación, por lo cual a ella se orienta la vida de la gracia presente en los no cristianos, entonces se vuelve evidente que a esa plenitud son invitados particularmente quienes se reconocen católicos.

Con respecto a la Biblia conviene hacer una salvedad, ya que la Palabra revelada llega a los fieles católicos de diversas maneras, y no exclusivamente a través del texto impreso en papel. El pueblo ha encontrado y lee también hoy el mensaje de la Biblia en las imágenes, los pesebres, las pinturas, las canciones, y en tantos espacios y expresiones que dicen el contenido revelado con otro lenguaje. No está determinado que esa luz de la Revelación deba llegar sólo por el contacto de los ojos con un papel escrito. De hecho durante siglos, en tiempos y lugares donde la mayoría de la población no sabía leer, el Evangelio llegó a ellos por esos caminos más sacramentales. Cuando Aparecida propone procurar que la piedad popular se enriquezca en un mayor contacto con la Biblia quiere ofrecer al pueblo sencillo el gozo y la fecundidad que hoy encuentran cada vez más cristianos en la lectura orante de la Biblia. Este contacto más cercano sin dudas es una riqueza deseable para todos, en orden a la maduración y el crecimiento de la fe y de la vida cristiana.

Pero tampoco podemos aplicar tan claramente a esta multitud de fieles lo que la RMi llama pastoral ordinaria, puesto que no se trata de los servicios que ordinariamente se brindan a los fieles que asisten con frecuencia a los centros católicos: confesión, acompañamiento espiritual, charlas, cursos de 
formación, predicación dominical, etc. La actividad misionera dirigida a los fieles de la piedad popular, que procura el crecimiento de su fe católica, toma otra forma completamente diferente que suele llamarse pastoral popular, y que tiene algunas características que la asemejan a la actividad misionera en un sentido más propio: ir a dónde ellos viven, hacer un peculiar esfuerzo de adaptación a su modo cultural, etc. Es decir, el movimiento de salir de las estructuras pastorales ordinarias para llegar a las periferias pobres se parece a la misión ad gentes en cuanto al modo, pero no en cuanto a la finalidad: No se trata de procurar una conversión a Jesucristo sino de acompañar, alentar y promover una fe católica viva, de manera que pueda seguir desarrollándose en el seno de la Iglesia Católica.

Hay que decir con toda claridad que la falta de atención, y a veces el desprecio de la piedad popular, no hacen más que propiciar que siga creciendo cada vez más ese sector que ya no se reconoce católico, sea para engrosar otras confesiones cristianas o, lo que es en realidad mucho más preocupante, para integrar el sector que más crece: el de los indiferentes y renegados. Salta a la vista, y no hay manera de negarlo, que la fe popular hoy no se retroalimenta de modo mágico e infalible. En América latina hay países de mayoría católica donde hoy los que se reconocen católicos son menos del $60 \%$. Si es admirable que en países como Brasil la fe católica se haya transmitido de modo espontáneo durante cinco siglos, en lugares donde sólo aparecía un sacerdote cada diez años o más, hoy está sucediendo que esa transmisión de la fe experimenta importantes condicionamientos, y ya hay más de un $35 \%$ que reniega del Catolicismo. Por eso el Documento de Aparecida reconoce con realismo que nuestras tradiciones culturales ya no se transmiten de una generación a otra con la misma fluidez que en el pasado. Ello afecta, incluso, a ese núcleo más profundo de cada cultura, constituido por la experiencia religiosa (DA 39). Hay que reaccionar a tiempo ante esta novedad, porque muchas veces, los lenguajes utilizados parecieran no tener en cuenta la mutación de los códigos existencialmente relevantes en las sociedades influenciadas por la postmodernidad y marcadas por un amplio pluralismo social y cultural. Los cambios culturales dificultan la transmisión de la fe por parte de la familia y de la sociedad (DA 100d).

Eso significa que, en un contexto donde el peso de los medios de comunicación como formadores de cultura es enorme, y donde el estilo de vida no facilita como en otras épocas la transmisión de la fe, la fe popular necesita un acompañamiento más cercano. Sería ingenuo y suicida ignorar estos cambios del sujeto social y las nuevas necesidades de las personas, que si no encuentran lo que buscan en estructuras católicas lo buscarán en otra parte. Hoy la fe popular requiere una atención que propicie caminos de maduración, crecimiento y afianzamiento, pero siempre habrá que hacerlo a partir de una profunda valoración de su identidad cultural propia: 
Conscientes de nuestra responsabilidad por los bautizados que han dejado esa gracia de participación en el misterio pascual y de incorporación en el Cuerpo de Cristo bajo una capa 'de indiferencia y olvido', se necesita cuidar el tesoro de la 'religiosidad popular' de nuestros pueblos, para que resplandezca cada vez más en ella 'la perla preciosa' que es Jesucristo, y sea siempre 'nuevamente' evangelizada (DA 549).

Un especialista en el tema, el Pbro. Rafael Tello, invitaba a establecer una distinción adecuada para respetar la modalidad propia de la pastoral popular. No es la tarea organizativa, donde la Iglesia se despliega con los recursos modernos, con todo su instrumental orientado a la formación de los fieles. A través de esta línea, valiosa, se llega sólo a un sector muy reducido de la población; sólo a un $5 \%$ si incluimos aquí a todos los que asisten frecuentemente a la Misa dominical. Con la intención de no llegar sólo a un pequeño grupo, sino a la mayoría, hay una segunda línea que consiste en brindar vías de expresión al catolicismo popular, que implica a la mayoría de la población en América Latina. Se trata aquí de la institución eclesial que, desde sus estructuras, llega al pueblo ofreciéndole espiritualidad, formas de culto, cercanía fraterna, una ayuda material, etc. Aquí se incluyen, por ejemplo, los actos masivos festivos, la organización de peregrinaciones, las misioneras parroquiales que llegan a todos los hogares, siempre desde la iniciativa de las estructuras eclesiásticas. Pero hay una tercera línea, poco desarrollada, que es la que más propiamente puede llamarse pastoral popular, y que no debe confundirse con la anterior, aunque también brinda vías de expresión al masivo catolicismo popular. La clave para distinguirla está en precisar quién es el sujeto que evangeliza, y si el pueblo se presenta sólo como receptor que acoge o también como sujeto creativo. Se trata de preparar 'los cuadros del mismo pueblo' para animar y fortalecer la evangelización activa del pueblo. ${ }^{7}$ La pastoral popular trabaja desde un cuadro popular, formado por gente del pueblo que, aun siendo católica, no actúa como miembro de la Iglesia institucional. Estos pueden actuar para lograr un objetivo puramente temporal (con un espíritu cristiano) o para un fin religioso (llevar la Virgen, organizar una fiesta religiosa) sin que por ello dejen de ser cuadro popular. ${ }^{8}$ Se trata entonces de aceptar y promover el surgimiento de líderes populares como agentes evangelizadores, respetando su modalidad propia y sus necesidades específicas.

7 Apuntes inéditos de Rafael Tello, en mi poder, titulados "Nueva Evangelización", págs. 62-63.

8 Ibíd, anexo I, pág. 47. 


\section{Misión ad gentes y nueva inculturación dentro de América Latina}

Esto no excluye la necesidad de esa otra manera de direccionar la actividad misionera que llamamos reevangelización o nueva evangelización, puesto que en América Latina también hay sectores, especialmente en las grandes ciudades, que ya no viven de modo explícito la fe católica, que están cada vez más lejos de alguna inserción eclesial, y, sobre todo, que ya no se reconocen como cristianos. Estos sectores están creciendo cada vez más, y reclaman de modo imperioso una nueva actividad misionera, un nuevo anuncio explícito de Jesucristo. No cabe aplicar esta noción de reevangelización sólo a los países europeos. Juan Pablo II utilizó por primera vez la expresión en 1979 en Puerto Príncipe (Haití) en su alocución a los obispos de América Latina.

Pero aun en los países de antigua cristiandad, incluyendo los de nuestro Continente, hay situaciones que reclaman no sólo una nueva evangelización sino en algunos casos una primera evangelización (RMi 37a). Hay que advertir que misión ad gentes y nueva evangelización son cosas sustancialmente distintas (RMi 37a), aunque no siempre se las pueda delimitar con precisión (ibíd). Los destinatarios de la misión ad gentes son espacios nuevos, que todavía no han acogido el primer anuncio y que se gestaron y desarrollan sin la luz del Evangelio. Ya AG 6 se refería al surgimiento de situaciones por completo nuevas con las que se encuentra la Iglesia, y que requieren de nuevo su acción misionera.

No podemos ignorar que en nuestros países está creciendo ese sector de la población caracterizado por el agnosticismo y por el escepticismo, y que ya hay jóvenes y adultos que han nacido y crecido en esos ambientes. Por eso, incluso en países tradicionalmente cristianos hay regiones confiadas al régimen especial de la misión 'ad gentes', grupos y áreas no evangelizadas (RMi 37a). No se trata necesariamente de sectores geográficos sino de nuevos areópagos para el primer anuncio, sectores que desarrollan su vida y su actividad prescindiendo completamente de Jesucristo y del Evangelio. A ellos se refiere RMi 39-40, mencionando como ejemplos ámbitos de la comunicación, la ecología, la cultura.

El anuncio en esos nuevos contextos es precisamente lo que puede brindar una novedosa riqueza a la Iglesia, un rostro inédito y más atractivo que viene del mismo fondo inagotable del Evangelio. Cuando su anuncio es acogido en una nueva situación la misma Iglesia universal se enriquece con expresiones y valores en los diferentes sectores de la vida cristiana [...], conoce y expresa aún mejor el misterio de Cristo, a la vez que es alentada a una continua renovación (RMi 52). Porque además de su valor 
antropológico implícito, todo encuentro con una persona o con una cultura concreta puede desvelar potencialidades del Evangelio poco explicitadas precedentemente ${ }^{9}$. Pero en definitiva la Iglesia se enriquece y se renueva porque, al llevar el anuncio a quienes no lo habían recibido, ella acoge en su seno la belleza y los bienes que hay en ellos. Este aspecto de la inculturación es una encarnación del Evangelio en las culturas, y a la vez, la introducción de éstas en la vida de la Iglesia (SA 21). El anuncio en los nuevos areópagos del mundo moderno y en los sectores no evangelizados de nuestras sociedades es entonces lo que permitiría a la Iglesia de hoy acoger una nueva riqueza y dar lugar a la renovación de su rostro que el Espíritu quiere realizar. América Latina, que enriqueció a la Iglesia universal a partir de la primera evangelización del Continente, está hoy en una encrucijada que será decisiva. $\mathrm{O}$ acoge el nuevo llamado misionero que le otorgará un nuevo atractivo a su rostro eclesial, o se irá reduciendo y empobreciendo paulatinamente.

\section{El nuevo llamado misionero}

Esta interpelación se dirige a todos. Para poner un ejemplo, veamos el caso del sacerdote diocesano. Él, como cualquier otro cristiano, y por el simple hecho de seguir siendo cristiano, está llamado a buscar particularmente a las personas que viven al margen de Jesucristo, lo desconocen, y no se reconocen miembros de la Iglesia:

Todos los sacerdotes deben estar abiertos 'sobre todo' a los grupos no cristianos del propio ambiente (PDV 32b). El Señor les confía no sólo el cuidado pastoral de la comunidad cristiana, sino también y 'sobre todo' la evangelización de sus compatriotas que no forman parte de su grey (RMi 67).

En este sentido, cualquier párroco debe asumir, como tarea fundamental, tan esencial e ineludible como el amor a Dios y al prójimo, la misión ad gentes en su propio territorio (ad intra). De ese modo recupera la dimensión estrictamente misionera, inseparable de su identidad cristiana, sin necesidad de salir de su propia diócesis. Porque no pueden ser misioneros de otros países o continentes, si antes no se preocupan seriamente de los no cristianos en su propia casa. La misión 'ad intra' es signo creíble de la misión 'ad extra' (RMi 34). Es indispensable advertir que la encíclica no se refiere aquí a la llamada pastoral ordinaria en el propio territorio, sino a la misión ad gentes en dicho territorio. No es lo mismo. Aparecida asume este

9 Congregación PARA LA Doctrina de LA Fe, Nota doctrinal acerca de algunos aspectos de la evangelización (cit), 6. 
llamado diciendo que no podemos quedarnos en espera pasiva en nuestros templos (DA 548).

Benedicto XVI reafirmó esta comprensión de la misión ad gentes, liberándola de una comprensión restrictiva, cuando sostuvo que el campo de la misión ad gentes se ha ampliado notablemente y no se puede definir sólo basándose en consideraciones geográficas o jurídicas. En efecto, los verdaderos destinatarios de la actividad misionera del Pueblo de Dios no son sólo los pueblos no cristianos y las tierras lejanas sino también los ámbitos socioculturales $y$, sobre todo, los corazones. ${ }^{10}$ No se trata de un viaje, sino de una no menos exigente salida de sí hacia el diferente. La firme recepción de Redemptoris Missio por parte de Aparecida, invita a desarrollar un perfil pastoral mucho menos encerrado en las estructuras eclesiales y mucho más capaz de salir, de acercarse, de entrar en la vida de las periferias geográficas y existenciales de su propio territorio. Por eso el párroco debe ser un ardoroso misionero que vive el constante anhelo de "buscar a los alejados' y no se contenta con la simple administración (DA 201). Esta nueva comprensión del llamado a la misión ad gentes dirigido a todos, no es algo sencillo, como si se tratara de un simple maquillaje, sino un verdadero reto que conmueve todas las estructuras personales y pastorales:

La conversión pastoral de nuestras comunidades exige que se pase de una pastoral de mera conservación a una pastoral decididamente misionera [...] haciendo que la Iglesia se manifieste como una madre que sale al encuentro, una casa acogedora, una escuela permanente de comunión misionera (DA 370).

Pero precisamente porque supone una conversión, requiere que el propio ser cristiano se mantenga vivo y sano. Si el agente pastoral no tiene la convicción real de que conocer a Cristo y tratarlo vale la pena, si el Resucitado no sigue siendo verdaderamente importante para él, si no sale de sí hacia Jesucristo dejándose alcanzar por él, no habrá interés sincero por llevar a otros a ese encuentro de amistad.

\section{La renovación extática, kerigmática y vocacional de la pastoral ordinaria}

Todo esto implica una renovación personal y eclesial. Pero precisemos ahora en qué consiste una renovación misionera dentro de nuestras diócesis. Podemos indicar 3 aspectos.

1) La renovación misionera de las comunidades es en primer lugar

10 Benedicto XVI, Discurso a las Obras Misionales Pontificias, 05/05/2007. 
una renovación extática (ex-tasis: salida de sí). Es decir, consiste en reestructurar las actividades, los grupos y los proyectos pastorales para poder llegar a las periferias, para salir hacia los que no conocen a Cristo y hacia los que están más abandonados. Esta renovación misionera que propone Aparecida tiene manifestaciones muy concretas, como multiplicación de servicios y ministerios misioneros (cf DA 202), superación de la burocracia (DA 203), sectorización en unidades territoriales más pequeñas (DA 372, 518c), creación de comunidades de familias (DA 372), etc.

Es un éxtasis, una salida, pero no para desarraigar, sino para crear nuevas formas de comunión, más ricas y más incluyentes de los que no se sienten convocados. Es salir para hacer nacer nuevos centros de arraigo y de fe compartida.

Eso implica, como ha dicho el Cardenal Bergoglio, aceptar y asumir un cierto desorden, una novedad que nos desinstala, que nos llama a una disponibilidad abierta, y nos expone a lo imprevisto. Se trata entonces de aceptar internamente ser desinstalados por lo inesperado (una profunda actitud espiritual).

2) Pero esto sería quedarse sólo en un primer nivel de la renovación eclesial que, aunque sea indispensable, todavía no nos permite llegar al fondo de una verdadera transformación misionera. Porque una renovación misionera profunda y realmente decisiva requiere también una renovación kerigmática que transfigure la pastoral ordinaria. Esto nos permite advertir que la propuesta de Aparecida no invita a descuidar la atención pastoral ordinaria, a vaciar las sedes parroquiales, sino a transformarla a la luz de la misión ad gentes.

¿Qué significa precisamente esto? La misión ad gentes es el paradigma de toda acción evangelizadora, es el primer analogado. Pues bien, la misión ad gentes está ordenada en primer lugar al kerigma. Es el anuncio del amor infinito de Dios que nos redimió en la Cruz de Jesucristo, quien ha resucitado y vive con nosotros. Vive y ofrece vida en abundancia, y está presente de tal manera que no nos abandona pase lo que pase. Su presencia puede darle un sentido a todo, hasta a la peor de las angustias, porque mi Redentor está vivo.

Estamos llamados a decirle esto de un modo u otro a cada persona, cara a cara. No hay que tener tanta vergüenza de presentar este anuncio. Es verdad, y nadie tiene derecho a relativizarlo o ridiculizarlo.

Pero no hay que entenderlo de un modo elitista o despreciativo de la fe de la gente. Este anuncio no se llama primero sólo en un sentido cronológico, como si nunca lo hubieran escuchado o comprendido. Se llama primero sobre todo en un sentido cualitativo. Es el anuncio fundamental y fundante, que debe estar presente siempre, atravesando todas las activida- 
des de la pastoral ordinaria. Cuando repetimos este anuncio a los fieles no lo hacemos pensando que nunca lo habían recibido, sino porque es la convicción principal que hay que renovar y afianzar constantemente, para que todo lo demás no se reduzca a un conjunto de normas, prácticas o ideas religiosas (cf. DA 12). Porque más que una decisión ética o una gran idea lo que configura el ser cristiano es un encuentro con un acontecimiento, con una Persona, que da un nuevo horizonte a la vida y, con ello, una orientación decisiva (DCE 1; DA 12, 243).

Precisamente por eso, los obispos en Aparecida han dicho que el amor vivificador de Dios que se nos ofrece en Cristo muerto y resucitado es lo primero que necesitamos anunciar y también escuchar (DA 348). Dicho esto por los obispos latinoamericanos, significa que aún el obispo necesita volver a escuchar aquello que siempre será lo primero.

La renovación kerigmática de la pastoral ordinaria nos vuelve a todos más misioneros. Pero eso implica renunciar a la idea de impartir a todos una formación minuciosa antes de enviar a alguien, o el ideal de concentrarse en pequeños grupos para darles una preparación exhaustiva. El anuncio elemental supone sólo una experiencia y una convicción, y eso se espera de cualquier cristiano, sin excepción. Se trata de llegar a todos a través de todos, con un renovado anuncio del kerigma, y no sólo a través de los que han recibido varios años de instrucción cristiana.

Pablo no esperó tener una formación cristiana completa para salir a anunciar a Jesucristo. En Mc 5, 20 el endemoniado liberado anuncia por todas partes lo que Jesús le dijo: Cuéntales lo que el Señor ha hecho por ti. Sin duda hay ministerios que requieren una formación prolongada, pero eso no vale para el anuncio misionero fundamental, que es obligación de todos. En todo caso, un misionero convencido de este anuncio, comienza a necesitar y a pedir una formación creciente para perfeccionar su actividad misionera.

Pero también hay que lograr que la actualización del primer anuncio esté presente constantemente en la predicación, la catequesis, la pastoral social, y en todas las áreas pastorales, iluminando y transformando toda la pastoral ordinaria.

Aun la celebración de los sacramentos puede dejarse interpelar por esta propuesta de renovación kerigmática. Eso implicaría aprovechar mejor las posibilidades misioneras que otorgan, particularmente, las celebraciones de bautismos y casamientos. Se trata entonces de situar el kerigma constantemente en el centro de la actividad pastoral:

El encuentro con Cristo que da origen a la iniciación cristiana [...] debe renovarse constantemente por el testimonio personal, el anuncio del kerigma y la acción misionera de la comunidad. El kerigma no sólo es una etapa, sino el hilo conduc- 
tor de un proceso que culmina en la madurez del discípulo de Jesucristo. Sin el kerigma, los demás aspectos de este proceso están condenados a la esterilidad, sin corazones verdaderamente convertidos al Señor. Sólo desde el kerigma se da la posibilidad de una iniciación cristiana verdadera. Por eso, la Iglesia ha de tenerlo presente en todas sus acciones" (DA 278a).

Sólo de esta manera los agentes pastorales estarán verdaderamente dispuestos para llevar ese anuncio a la vida pública y a las periferias de la sociedad, con verdadera convicción.

Los presbíteros, así como deben alentar la comunión fraterna en todos los sectores de la actividad pastoral, también están llamados a asegurar esta constante renovación kerigmática. Esto no complica su ministerio ni lo vuelve más pesado. Al contrario. Cuando un presbítero vuelve al núcleo de su fe, no tiene temor a complicar su vida con un montón de exigencias nuevas. Simplemente retorna al manantial más fresco y puro, y orienta a los demás en ese mismo sentido. Así, no sólo se simplifica y renueva su vida cristiana sino la de toda la comunidad.

Como consecuencia, se deja de perder tiempo y energías en cosas internas, preocupaciones secundarias, discusiones inútiles, estructuras asfixiantes, y las energías se encauzan en lo esencial. Por eso, no se trata de sobrecargar todavía más su agenda, sino de adoptar un nuevo estilo, que libera al cura de pesos inútiles y a la vez lo vuelve más fecundo.

De otra manera, el miedo a la misión nos mantiene encerrados en pequeños sectores algo enfermizos, y desarrollamos una vida parroquial entrópica, involutiva, que no tiene más futuro que enfriarse todavía más y destruirse poco a poco a sí misma. Es un círculo vicioso de mezquindad llena de excusas. Hay que convencerse de que la vida se acrecienta dándola (DA 360).

3) La renovación misionera tiene también un tercer aspecto, el vocacional: Para que haya una misión permanente hay que partir de una base, y es que todos estén convencidos de que su vida misma es una misión para los otros, de que el Dios amante los envía a los demás, y eso es lo que da sentido a su paso por este mundo. ¿Para qué estás en esta tierra si no es para cumplir una misión? Por ello, toda auténtica renovación misionera exige diversos espacios donde se ofrezcan constantes motivaciones para que la gente se decida con gusto por la misión desde su vocación específica. ${ }^{11}$

11 Para promover esta acción motivadora, recientemente publiqué el libro Quince motivaciones para ser misioneros, edit. Claretiana, Buenos Aires, 2008. 


\section{La dimensión discipular de la propuesta}

Las modificaciones estructurales de la Iglesia para que responda mejor a su naturaleza misionera serán infecundas si no se alimenta un determinado espíritu. Es verdad que esto implica desarrollar y difundir las motivaciones más profundas que estimulen la entrega misionera. Pero, detrás de todas estas motivaciones, si se quiere otorgar seriamente el lugar que corresponde al anuncio explícito de Jesucristo, hay que reconocer la necesidad de fortalecer siempre la identidad discipular de cada creyente. Aunque yo mismo tenía ciertos reparos ante un acento exagerado en el discipulado, ahora reconozco la necesidad de entender el auténtico e indispensable aporte de este acento. Concebirse a sí mismo como discípulo es condición necesaria para ser auténtica y establemente misioneros, porque cuando crece la conciencia de pertenencia a Cristo, en razón de la gratitud y alegría que produce, crece también el ímpetu de comunicar a todos el don de ese encuentro (DA 145). Pero esto, en definitiva, responde a nuestra realidad profunda de ser criaturas, que no hemos comprado la vida sino que la recibimos gratuitamente, y que en nuestro núcleo más profundo sólo podemos recibir. Lo mismo decimos de la amistad con Jesucristo, que no puede ser merecida ni pagada, sino sólo acogida como don. Por eso Aparecida insiste en presentar la identidad del cristiano como discipulado. Su valor está en que, mientras la misión destaca la dimensión centrífuga-donativa de la vida en Cristo, el discipulado permite percibir su dimensión receptiva. Por eso se dice que el amor vivificador de Dios que se nos ofrece en Cristo muerto y resucitado es lo primero que necesitamos anunciar ' $y$ también escuchar' (DA 348) y que sólo gracias a ese encuentro y seguimiento, que se convierte en familiaridad y comunión, por desborde de gratitud y alegría, 'somos rescatados' de nuestra conciencia aislada y salimos a comunicar a todos la vida verdadera (DA 549).

El Papa había subrayado esta dimensión al decir que la Iglesia es misionera en cuanto discípula, es decir, capaz de 'dejarse atraer' siempre, con renovado asombro, por Dios que nos amó y nos ama primero. ${ }^{12}$

La bella alabanza a Dios por la vida (DA 106-113) expresa esta actitud receptiva, reconociendo todo lo que vivimos como don de Dios que acogemos agradecidos. En estos pocos párrafos, la expresión don/es aparece 7 veces. Por supuesto, a partir de esta actitud receptiva ante el amor de Dios, se desencadena un nuevo dinamismo de cooperación en el cual el discipulado involucra todas las aptitudes y la creatividad activa del ser

12 Benedicto XVI, Homilía en la Misa de Inauguración de la V Conferencia, $13 / 05 / 2007$. 
humano. Pero también detrás de ese proceso hay que reconocer un don: La propia vocación, la propia libertad y la propia originalidad son dones de Dios para la plenitud y el servicio del mundo (DA 111). El origen y el núcleo permanente del discipulado es una serena y feliz receptividad ante el amor de Dios. ${ }^{13}$

Advirtamos que el discipulado no es simplemente un conjunto de prácticas piadosas, con las cuales podrían disimularse formas sutiles de pelagianismo. Es más que eso, es una actitud que está detrás de la oración misma y sin la cual las prácticas espirituales podrían ser sólo un modo como Satanás se disfraza de ángel de luz (2 Co 11, 14). Me refiero a la actitud de aceptar depender de Dios, de reconocer la necesidad de él y abandonar las resistencias que no nos permiten vivir de él.

Todo el que desee vivir una experiencia plenificadora del amor de Dios, debería pedir la gracia de dejarse amar, de abandonar sus defensas y su pretensión de autonomía. En la raíz de todo auténtico camino cristiano está el intento de aceptar esa dependencia de Dios que sólo lograremos plenamente después de la muerte, porque nuestra fragilidad de creaturas siempre se resistirá.

En la verdadera experiencia mística, Dios toca un centro amoroso donde la persona humana sólo puede depender, porque es una criatura y lo más íntimo de su realidad es la dependencia, es recibir el ser y la vida, es beber de Dios. En la aceptación sincera de esta dependencia -en el ser y en la gracia- se juega toda forma auténtica de discipulado. El discípulo es ante todo el que escucha, el que acoge, el que se deja llevar, guiar, transfigurar según la imagen del Maestro. Es quien se reconoce necesitado y acepta serena y gozosamente recibir del Maestro. Esta actitud se expresa en la oración, en la lectura de la Palabra, en la docilidad para dejarse formar -por Dios, por los demás, por la vida-.

Sin esta actitud básica de apertura discipular, no es posible ni la recepción, ni la maduración, ni la comunicación de la vida que Cristo ofrece. Por eso, estamos ante otra estructura básica de una vida digna y plena. En definitiva, lo que nos define no son las circunstancias dramáticas de la vida, ni los desafíos de la sociedad, ni las tareas que debemos emprender, sino ante todo el 'amor recibido' del Padre gracias a Jesucristo por la unción del Espíritu Santo (DA 14).

Nadie puede ignorar que, cuando se enfría el amor por Cristo, cuando ya no nos cautiva meditar el Evangelio, cuando el encuentro con él deja de atraernos y cuando su figura deja de fascinarnos, no puede haber un inte-

13 J. A. SAYÉS, La gracia de Cristo, Madrid, 1993, 181. 
rés genuino de hablar de él, de llevarlo a los demás. Comenzamos a pensar que son otras cosas las que un ser humano necesita hoy para realizarse, y por lo tanto no nos interesa gastar nuestro tiempo en el anuncio. Entonces, para convertirnos en una Iglesia llena de ímpetu y audacia evangelizadora, tenemos que ser de nuevo evangelizados (DA 549).

El Documento acoge aquella firme afirmación de Benedicto XVI en su Discurso inaugural cuando dijo que discipulado y misión son como dos caras de una misma medalla (DA 146). Pero en la práctica discipulado y misión son inseparables porque el auténtico discipulado es una mirada verdaderamente contemplativa a Jesucristo. Pero realmente contemplativa, hasta el fondo. Tan contemplativa que nos hace participar de la mirada de Jesús hacia los abandonados, amados y buscados por él, que ha querido necesitar de nuestra cooperación para llegar a ellos. Una mirada tan hondamente contemplativa que nos saca de nosotros mismos hasta reconocer y aceptar de corazón su envío misionero: Vayan por todo el mundo y anuncien el Evangelio (Mc 16, 15). Tan fuertemente contemplativa que nos permita volver a reconocer que el mismo amor de Cristo nos apremia a ser misioneros (cf. 2 Co 5, 14), hasta el punto que llegamos a decir: ¡Ay de mí si no anuncio el Evangelio! (1 Co 9, 16). Aparecida, para alentar un nuevo compromiso misionero, nos invita a todos a volver a convencernos de que Jesucristo vale la pena. Nos propone que nos atrevamos al vértigo de vivir de él y para él en medio del vacío posmoderno. Nos convoca, de esta manera, a volver a hablar de él sin vergüenza ni complejos, sabiendo que su amor, que nos hace tanto bien, nos llama a recomenzar con entusiasmo en la misión de comunicar su vida:

Los cristianos necesitamos recomenzar desde Cristo, desde la contemplación de quien nos ha revelado en su misterio la plenitud del cumplimiento de la vocación humana y de su sentido. Necesitamos hacernos discípulos dóciles, para aprender de Él, en su seguimiento, la dignidad y plenitud de la vida" (DA 41).

En definitiva, se trata de atreverse a volver a la esencia de la propia vocación. Alguna vez quisimos entregarle la vida a Jesucristo con un profundo deseo de hacer el bien a los demás, de convertirnos en una especie de cántaro de vida donde los demás pudieran ir a refrescarse y a beber. Queremos recuperar la ilusión y devolverle a nuestra vida cristiana esa dimensión misionera que le viene de la radical vocación cristiana.

\section{Agentes pastorales cargados de propuestas de vida}

Sin duda, junto a la convocatoria misionera, el gran eje del tema de Aparecida es para que tengan vida. El para qué indica la finalidad de toda la acti- 
vidad de la Iglesia: La propuesta de Jesucristo a nuestros pueblos, 'el contenido fundamental de esta misión', es la oferta de una vida plena para todos (DA 361). Por eso la Iglesia tiene como 'misión propia y específica' comunicar la vida de Jesucristo a todas las personas (DA 386). Puesto que los cristianos somos portadores de buenas noticias para la humanidad y no profetas de desventuras (DA 30), se quiere mostrar que la relación con Jesucristo no nos hace menos felices, no nos exige que renunciemos a nuestros anhelos de intensidad vital, sino que nos ayuda a desarrollarnos plenamente y a disfrutar más y mejor de la existencia, porque él ama nuestra felicidad 'también en esta tierra' (DA 355). Es una afirmación que parece obvia, pero que pocas veces aparece explicitada en la predicación y suele estar ausente de las convicciones reales de muchos creyentes.

Se trata de una vida que no puede clausurarse en el sujeto sino que por su propia naturaleza tiende a comunicarse a otros. La misión se presenta así como una consecuencia directa de una existencia bien vivida. Tomando este punto de partida positivo ante los anhelos humanos, se quiere mostrar que una vida digna y feliz no se realiza en el aislamiento y en la comodidad individualista. El Documento recuerda que una ley de la vida es que la vida crece en la medida en que uno la comunica por amor (DA 358-360). Además del texto de Jn 10, 10, que expresa esta voluntad de Cristo de traernos vida en abundancia, se menciona $1 \operatorname{Tim} 6,17$, para indicar que esa vida incluye el legítimo disfrute de las cosas de este mundo (cf. DA 355). Este sentido integrador se desarrolla inmediatamente a partir de una cita del Discurso inaugural de Benedicto XVI (n. 4), diciendo que la vida nueva de Jesucristo desarrolla en plenitud la existencia humana en su dimensión personal, familiar, social y cultural, con lo cual él se manifiesta como nuestro Salvador 'en todos los sentidos de la palabra' (DA 356).

Para ser más explícito todavía y no dejar lugar a dudas, el Documento se detiene a enumerar algunas expresiones de este sentido integrador de la vida en Cristo:

La vida en Cristo incluye la alegría de comer juntos, el entusiasmo por progresar, el gusto de trabajar y de aprender, el gozo de servir a quien nos necesite, el contacto con la naturaleza, el entusiasmo de los proyectos comunitarios, el placer de una sexualidad vivida según el Evangelio, y todas las cosas que el Padre nos regala como signos de su amor sincero (DA 356).

Es novedoso que un Documento episcopal diga que la vida en Cristo incluye el entusiasmo por progresar y el placer de la sexualidad. Así queda claro que la fe católica no pretende hacer sufrir a las personas o limitar su felicidad legítima. Más bien se trata de mostrar la profunda unidad que existe entre la amistad con Jesucristo y el ideal humano de felicidad y plenitud vital. Si muchas veces se creó una dañina dialéctica entre la fe y 
nuestra vida terrena, en Aparecida se sostiene que todo signo auténtico de verdad, bien y belleza en la aventura humana viene de Dios y clama por Dios (DA 380). Esta convicción debería incorporarse explícitamente en el anuncio del Evangelio, y trasfigurar la predicación, porque la doctrina, las normas, las orientaciones éticas, y toda la actividad misionera de la lglesia, debe dejar transparentar esta atractiva oferta de una vida más digna, en Cristo, para cada hombre y para cada mujer de América Latina y de EI Caribe (DA 363). La necesidad de aplicar esta convicción en la pastoral ordinaria aparece también en otra parte del Documento, donde se dice que no se concibe que se pueda anunciar el Evangelio sin que éste ilumine, infunda aliento y esperanza, e inspire soluciones adecuadas a los problemas de la existencia (DA 333). Encontramos así un criterio de discernimiento para reconocer un adecuado anuncio del Evangelio y una actividad pastoral que responda a la naturaleza de ese anuncio.

De ningún modo se quiere proponer un hedonismo que nos clausure en la inmanencia, sino más bien que incluso en medio del placer y la intensidad vital se haga presente a Dios, para darle a todo su último sentido. Por eso se sostiene que podemos encontrar 'al Señor' en medio de las alegrías de nuestra limitada existencia (DA 356). Tampoco se ignora que el gozo del momento presente puede llegar a ser vivido de un modo inadecuado, que absorba todas nuestras posibilidades vitales, limite nuestras perspectivas e impida el desarrollo de nuestras mejores potencialidades:

La vitalidad que Cristo ofrece nos invita a ampliar nuestros horizontes [...] A la Samaritana le da más que el agua del pozo, a la multitud hambrienta le ofrece más que el alivio del hambre. Se entrega Él mismo como la vida en abundancia. La vida nueva en Cristo es participación en la vida de amor del Dios Uno y Trino. Comienza en el bautismo y llega a su plenitud en la resurrección final (DA 357).

Pero es necesario volver a cerrar el círculo, para no entender esta plenitud espiritual de un modo dialéctico, como si la apertura a la trascendencia fuera una autoinmolación donde lo humano es negado. Entonces hay que recordar que su amistad no nos exige que renunciemos a nuestros anhelos de plenitud vital, porque Él ama nuestra felicidad también en esta tierra (DA 355), que Cristo no quita nada (DA 15; 352) y que buscando la santidad no vivimos menos, sino mejor, porque cuando Dios pide más es porque está ofreciendo más (DA 352).

Si desde la fe no queda revalorizado el mundo de la vida, si la religión y su posición moral se presentan como dimensiones contrarias a lo corporal, al respetuoso sentido sexual de la persona o al disfrute correctamente entendido de la existencia, que gratuitamente ha sido regalada al hombre y a la mujer, nos hallamos ante un raro horizonte. Si no se favorece el deseo y el gusto de habitar en el mundo en sus más nobles posibilidades de que los hombres y las mujeres alcan- 
cen su realización como personas, la religiosidad tendrá poco sitio en el futuro y será mal vista como un ámbito revestido de negativo recelo. ${ }^{14}$

Esto es así no porque la gente haya aprendido a disfrutar de la vida, sino más bien lo contrario, porque busca estímulos para ser feliz, ya que estamos más preparados para sufrir que para gozar ${ }^{15}$ y nos da más miedo el disfrute de la vida, que el dolor que puede causarnos. ${ }^{16}$ Otra vez, con una perspectiva integradora, no se intenta echarle agua al vino sino convertir el agua en vino, asumiendo para redimir. Ante un sujeto que tiende a clausurarse en sí mismo y en el cuidado de su mundo privado y del placer inmediato, Aparecida no opta por criticar ácidamente al mundo de hoy con calificativos lacerantes, ni quiere insistir en la mortificación o en el sacrificio. Sabemos que estas opciones pastorales hoy dan poco resultado y provocan un mayor rechazo de la mayoría de los interlocutores, que llegan a pensar que la propuesta de la Iglesia es enemiga de toda vida feliz. Hoy, para ser escuchados, es necesario comunicar los valores evangélicos de manera positiva y propositiva (DA 497). Por eso, la estrategia de Aparecida ha sido más bien tomar un punto de partida positivo, reconociendo los legítimos anhelos de dignidad y de felicidad de nuestros pueblos, y mostrando cómo la misma Palabra de Dios invita a una vida digna y feliz. Pero se hace cargo de la degradación del sujeto posmoderno intentando mostrar las verdaderas estructuras de esa vida digna y plena, que sólo se desarroIla cuando se dan determinadas condiciones. Su opción es penetrar en el seno mismo de la vida digna y feliz para descubrir allí las leyes que la estructuran y la hacen verdaderamente posible: su dinamismo comunitario, discipular y misionero.

\section{Misión, dignidad humana y espiritualidad contra la obsesión por el tiempo}

Esta orientación de la evangelización a la comunicación de la Vida permite proponer un atractivo perfil de los cristianos como instrumentos de una vida digna y plena para el pueblo. Deberían ser entonces agentes pastorales cuya predicación y cuyas propuestas manifiesten, con rostro amable y cercano, la oferta de vida del Evangelio, y que sepan hacer derivar de la Eucaristía todas sus exigencias de compromiso comunitario para la vida digna y plena de los pueblos.

14 G. MuntANER, La novedad como estímulo, Estella, 2005, 86.

15 Ibíd.

16 Lo desarrolla el neurólogo LL. BARRAQUER I BordAs, "A propòsit del cos i de la sexualitat", en AA VV, El catolicisme a debat, Abadía de Monserrat, 2002, 111-116. 
La propuesta de una misión dirigida a las periferias y la comprensión de la misión como promoción de una vida digna y plena en Cristo, exigen retomar la opción preferencial por aquellos que no pueden vivir adecuadamente. Por eso, cuando Aparecida se detiene a explicar por qué esta opción es preferencial explica que debe atravesar todas nuestras estructuras y prioridades pastorales (DA 396). Pero invita a pasar de una opción meramente intelectual o emotiva a un compromiso real, a hacerse amigos de los pobres (DA 257), a una cercanía que nos hace amigos (DA 398), ya que hoy defendemos demasiado nuestros espacios de privacidad y disfrute, y nos dejamos contagiar fácilmente por el consumismo individualista. Por eso, nuestra opción por los pobres corre el riesgo de quedarse en un plano teórico o meramente emotivo, sin verdadera incidencia en nuestros comportamientos y en nuestras decisiones (DA 397). Así se dibuja el perfil de un agente pastoral que sale hacia las periferias abandonadas y en la distribución de su tiempo opta claramente por aquellos que, teniendo una dignidad infinita (DA 388), viven en condiciones que contradicen esa dignidad. Esta opción por volverse cercano no tiene el sentido de procurar éxitos pastorales, sino de la fidelidad en la imitación del Maestro, siempre cercano, accesible, disponible para todos, deseoso de comunicar vida en cada rincón de la tierra (DA 372).

El reconocimiento de la dignidad infinita o del valor sagrado de cada sujeto es un componente indispensable de toda renovación misionera efectiva. Hay que descubrir que esta honda convicción sobre el valor sagrado de cada individuo no sólo es necesaria para apuntalar la opción por el más pobre, sino simplemente para sostener la opción por el ser humano que debe estar detrás de toda opción misionera.

No es casual que inmediatamente después del capítulo dedicado a la misión, el Documento de Aparecida consagra otro capítulo a la dignidad humana. No se trata simplemente de repetir el principio ya consagrado de la íntima unidad que hay entre evangelización y promoción humana. Tiene que ver también con una característica de los sujetos de hoy. Porque los sujetos posmodernos sólo dedicamos tiempo a las personas que valoramos, y la decisión por la misión, en este contexto sociocultural, es particularmente una cuestión de tiempo. Por eso mismo, Aparecida reformula la opción por los pobres como una decisión de dedicar tiempo a los pobres (DA 397), concretamente horas, semanas o años de nuestra vida (Ibid).

Por otra parte, la clásica conexión entre evangelización y promoción social, en Aparecida asume un nuevo rostro, acorde con los signos de los tiempos, y se perfila como conexión entre espiritualidad y compromiso socialmisionero. El acento puesto en el discipulado otorga a todo el documento un tono espiritual acorde con la nueva sed de espiritualidad propia de estos 
tiempos. Pero son oportunos los puntos 284-285, que invitan a desarrollar una noción adecuada de espiritualidad, que no nos aparte de la entrega generosa sino que la alimente y la sostenga:

No es una experiencia que se limita a los espacios privados de la devoción, sino que busca penetrarlo todo con su fuego y su vida. El discípulo y misionero, movido por el impulso y el ardor que proviene del Espíritu, aprende a expresarlo en el trabajo, en el diálogo, en el servicio, en la misión cotidiana (DA 284).

Así, la vida en el Espíritu no nos cierra en una intimidad cómoda, sino que nos convierte en personas generosas y creativas, felices en el anuncio y el servicio misionero. Nos vuelve comprometidos con los reclamos de la realidad y capaces de encontrarle un profundo significado a todo lo que nos toca hacer por la Iglesia y por el mundo (DA 285).

La debilidad de los sujetos evangelizadores no se resuelve hoy contraponiendo despreciando la espiritualidad por resaltar la necesidad de una acción donativa generosa, sino armonizándolas adecuadamente para que se alimenten y se potencien entre sí. 